\footnotetext{
* Doutora em Direito em 2015 pela Pontificia Universidad Católica de Chile (UC - CL).

Mestre em Ciência Jurídica em 2010 pela Pontificia Universidad Católica de Chile (UC - CL).

Graduada em Direito em 2002 pela Universidad de Talca (UTALCA- CL).

E-mail: yotarola@uandes.cl
}

\section{EL DESARROLLO DEL SISTEMA DE REPARACIÓN DE LOS DAÑos ENTRE CóNYUGeS EN EL DERECHO ESPAÑOL}

\author{
THE DEVELOPMENT OF THE SYSTEM OF REPAIR OF DAMAGES \\ BETWEEN SPOUSES IN SPANISH LAW
}

Yasna Elizabeth Otarola*

Como citar: OTAROLA, Yasna Elizabeth. El desarrollo del sistema de reparación de los daños entre cónyuges en el derecho español. Scientia Iuris, Londrina, v. 22, n. 3, p. 160-180, nov. 2018. DOI: $10.5433 / 2178-8189.2018 v 22 n 3 p 160$. ISSN: 21788189.

Resumen: El artículo analiza y evalúa el desarrollo que ha experimentado el Derecho español respecto de la admisión de la reparación del daño provocado por el incumplimiento de los deberes matrimoniales con el objeto de determinar si el sistema acepta la indemnización y, por ende, si ha incorporado el principio de la reparación en el Derecho Matrimonial español.

Palabras claves: Responsabilidad civil- Incumplimiento marital- Indemnización de perjuicios.

Abstract: The article analyzes and evaluates the development that Spanish Law has experienced regarding the admission of compensation for the damage caused by the breach of matrimonial duties to determine if the system accepts the compensation and, therefore, if it has incorporated the principle of the repair in Spanish matrimonial law.

Keywords: Civil liability- Marital breach- Compensation for damages 


\section{INTRODUCCIÓN}

En el Derecho Español, los pronunciamientos jurisprudenciales en los que se concede una indemnización a favor del cónyuge que ha sufrido daño por el incumplimiento de los deberes conyugales por parte del otro se han caracterizado por proporcionar una protección limitada, solo para algunos tipos de daños que se dan en circunstancias y con requisitos muy concretos. Y si bien en un primer momento los jueces se mostraron reacios a resarcir este tipo de daños, al estimar que aquellos que eventualmente podían desencadenarse de tal transgresión no son indemnizables, en la actualidad esta doctrina, al parecer, ha cambiado.

Sobre la base de una interpretación limitada del criterio general de imputación de responsabilidad, esto es, la culpa, sin distinción de grados, según resulta del artículo 1902 del Código Civil español, se ha resuelto que en el Derecho de Familia únicamente serán resarcidos aquellos daños que, originados en el ámbito matrimonial, su producción obedece a que el autor del hecho ha incurrido, no en una diligencia media, sino en dolo o culpa grave, pues de otro modo los tribunales se verían obligados a conocer de demandas de indemnización de perjuicios basadas en la alegación de incumplimientos triviales de las obligaciones conyugales (CARRASCO, 2008; LLAMAS POMBO, 1999).

A esta interpretación se agrega una objeción nacida no solo de la jurisprudencia, sino también de una parte importante de la doctrina que, en ese momento, advertía que si bien dicha infracción es capaz de producir daños patrimoniales y no patrimoniales - morales- distintos del mero incumplimiento, no es posible aplicar las normas que regulan la responsabilidad contractual. Primero, porque el matrimonio no es un contrato y los deberes conyugales no son obligaciones que emanen de él, sino tan solo las consecuencias o efectos jurídicos expresamente tipificados por el legislador, segundo, debido, especialmente, a que entiende que los deberes conyugales, si bien tienen reconocimiento jurídico, su contenido es más ético y social, lo que conlleva a que su cumplimiento dependa más de la conciencia de los individuos que de su coercibilidad jurídica, determinando de forma contundente que la infracción de dichos deberes no origina ningún derecho a indemnización.

En este contexto, se ha propuesto analizar y evaluar el desarrollo que ha experimentado el Derecho español respecto de la admisión de la reparación del daño provocado por el incumplimiento de los deberes matrimoniales con el objeto de determinar si el sistema acepta la indemnización y por ende ha incorporado el principio de la reparación en el Derecho Matrimonial español.

En ese empeño, en primer lugar, se describe la posición inicial de la doctrina y la jurisprudencia respecto a la posibilidad de reparar a través de la indemnización el daño provocado por el incumplimiento matrimonial. En segundo lugar, las razones que, con posterioridad a la reforma del año 2005, justifican que los tribunales hayan decidido condenar a pagar una indemnización. Finalmente, se analiza el asidero de las objeciones que pretender limitar la reparación.

\section{LA POSICIÓN DE LA DOCTRINA}


En tal sentido, ha de admitirse que no existe acuerdo unánime en la doctrina española en torno a las objeciones que en principio ha planteado la jurisprudencia, esto es, la naturaleza no jurídica de los deberes conyugales; los criterios de imputación necesarios para indemnizar el daño provocado por el incumplimiento de los deberes matrimoniales; la aplicación exclusiva de las acciones de Derecho de Familia y la vía para exigir la indemnización.

En este contexto, un grupo de autores opina que los deberes conyugales son obligaciones impuestas por el ordenamiento jurídico a través de normas pertenecientes al Derecho de Familia. De lo contrario, no tendría razón que el Código Civil los incluyera entre los efectos del matrimonio, ni que legalmente fueran calificados como tales por los artículos 67 y 68 de dicho texto legal que, al enunciarlos, habla de que los cónyuges "deben” o "están obligados” a cumplirlos. Precisamente, agrega que la significación jurídica de tales deberes es la razón por la cual los contrayentes tienen que asumirlos, al tiempo de prestar su consentimiento, y que su transgresión genera, como cualquier otra obligación, el deber de reparar a través de la indemnización si se ha causado un daño patrimonial o moral (NOVALES ALQUEZAR, 2006; DE VERDA Y BEAMONTE, 2003).

A mayor abundamiento, se ha esgrimido que el matrimonio restringe en su ámbito la expresión de la personalidad de cada cónyuge, quien, en cierta medida y libremente, deja de serlo, precisamente porque, como expresa Rogel Vide (2005, p. 562) "en la concepción europea tradicional, marido y mujer se hallan vinculados en una comunidad total e íntima -'consortium omnis vitae'- al cual ha de subordinarse la espontaneidad y el arbitrio de los partícipes." En consecuencia, si los cónyuges -según Rogel- han contratado al celebrar el matrimonio y, por lo tanto, han quedado vinculados jurídicamente entre sí, la idea de vínculo sugiere, inmediatamente, que se está obligado a llevar a cabo un comportamiento determinado a favor de otra u otras personas; quien se casa, está renunciando voluntariamente a la libertad y quien desea recuperarla debe indemnizar el daño que pueda provocar al otro.

De acuerdo con las normas generales de responsabilidad civil, en estas situaciones deberán aplicarse las reglas sobre el incumplimiento de las obligaciones contractuales y, en último término, las relativas al ilícito civil, porque el matrimonio si bien es intuito personae y personalísimo, en un sentido amplio es un contrato, es decir, como acuerdo de voluntades; pero no en su acepción rigurosa, que se reduce a los acuerdos de voluntades en materia patrimonial. Esta es la razón por la que no puede reclamarse el cumplimiento mediante su imposición coactiva por parte del Estado, en concreto, a través de la ejecución forzada de las obligaciones. ${ }^{1}$ Por otra parte, incluso en el ámbito de los negocios de carácter patrimonial, se excluye la ejecución de las obligaciones contractuales en los casos en los que la naturaleza de la obligación o su carácter personalísimo hacen inviable tal ejecución (PASTOR VITA, 2005, p. 33).

En este orden de cosas, tal carácter sitúa el incumplimiento de los deberes matrimoniales

\footnotetext{
1 Respecto de los artículos 67 y 68 del Código Civil español, se ha señalado que aunque, "en los mismos se hable de los deberes de los cónyuges, [...] lo cierto es que difícilmente puede constreñirse al cumplimiento de unas y otros, al margen de que, en no pocas ocasiones, el incumplimiento no sea ni tan siquiera constatable, por producirse al interior de las conciencias. Ciertamente, las conductas más contradictorias con los dichos deberes y con los buenos tratos que, de su cumplimiento se derivan para los cónyuges son sancionables, tienen consecuencias en la vía civil e incluso, en la penal.”(ROGEL VIDE, 2005, p. 563).
} 
dentro del amplio espectro de la responsabilidad civil contractual u obligacional, que comprende otros supuestos distintos del contrato en sentido estricto, siempre que haya un ligamen o vínculo jurídico previo, cualquiera que sea su fuente. Por otro lado, y como consecuencia de lo anterior no debe descartarse la facultad de demandar por dicha vía la reparación del daño moral sufrido por el incumplimiento de los deberes matrimoniales, considerando, además, la general aceptación que hoy en día tiene la reparación de ese daño en sede contractual.

Otros, en tanto, si bien comparten la tesis de aceptar la indemnización, la han matizado, señalando que en la medida en que el incumplimiento origine un daño que se pueda reputar como injustamente causado, aunque los deberes jurídicos no tengan carácter patrimonial, podrá ser resarcido a través de medios o instrumentos que logren la satisfacción económica, si se dan los requisitos para exigir responsabilidad (DÍEZ-PICAZO Y GULLÓN, 2002). De este modo, la transgresión de los deberes matrimoniales sí puede originar un daño moral susceptible de ser indemnizado en sede extracontractual, pero dependerá del caso concreto, y más bien considerando los factores de gravedad, reiteración y consecuencias que deriven de ella, si se vulneran derechos o bienes del otro cónyuge dignos de tutela jurídica. El criterio de imputación, en este caso, a diferencia del de la responsabilidad civil, según resulta del artículo 1902 del Código Civil, es el dolo o al menos la culpa grave, según se desprende de la regulación establecida para las situaciones de familia en el Derecho español. ${ }^{2}$

Finalmente, respecto de si pudiese aplicarse igualmente, al menos como posibilidad teórica, la normativa general de la responsabilidad civil extracontractual, artículos 1902 y siguientes del Código Civil español, no obstante, los supuestos en que este prevé acciones que otorgan una forma especial de resarcimiento, se considera que es posible, aunque tal aplicación no ha de ser automática, sino matizada en virtud de las características propias del ámbito familiar. Todo ello porque no todo el daño efectivamente causado con la nulidad, la separación o el divorcio entre cónyuges es objeto de compensación económica mediante los artículos 97 y 98 del Código Civil español. Con el artículo 98 solo se indemnizan daños materiales al cónyuge de buena fe que sufre la nulidad; igualmente, el artículo 97 solo repara de forma limitada los daños patrimoniales y exclusivamente aquellos que sean resultado del desequilibrio económico que resulte de comparar la situación anterior y posterior al divorcio. Y tampoco contempla los daños morales, tales como los perjuicios de naturaleza psicológica y espiritual que inevitablemente puede producir la ruptura matrimonial. ${ }^{3}$ De esta manera, las normas de responsabilidad civil pueden complementar la

2 Aunque la segunda tesis sostiene que la responsabilidad civil en el ámbito familiar no solo se origina cuando el agente del daño ha incurrido en dolo, sino también cuando ha incurrido en culpa grave. Tal posición encuentra apoyo en ciertos preceptos del ordenamiento jurídico español que regulan daños entre cónyuges, vigente el matrimonio y que se rigen por la sociedad de gananciales: artículos 1390 y 1391 del Código Civil. Sin embargo, algunos consideran que de estos preceptos no puede derivarse la regla general sobre los criterios de imputación de responsabilidad civil aplicables a cualquier daño entre familiares. Fundamentalmente porque este tipo de preceptos del Código Civil, ubicados en la normativa reguladora del Derecho de Familia, que prevén el resarcimiento del daño como medida, solamente cabe aplicarlos al supuesto especial que regulan, que suele ser muy concreto (RODRIGUEZ GUITIÁN, 2011). Concuerdan con los criterios de imputabilidad (NIETO ALONSO, 2006; GARCÍA DE LEONARDO, 2006; FERRER RIBA, 2003).

3 Tras la nueva redacción del artículo 97 del Código Civil por la Ley 15-2005, de 8 de julio, estas conclusiones acerca de su cobertura limitada de los daños no han variado, sino que se han reforzado. De los debates parlamentarios en los que se aprueba finalmente la citada ley se deduce, sin ninguna duda, que no se indemnizan los daños morales ocasionados por el incumplimiento de los deberes matrimoniales. Durante dichos debates se rechaza la enmienda 
protección limitada que el Derecho de Familia entrega.

En definitiva, dada la protección limitada y que ningún precepto del Código Civil restringe las acciones ejercitables a las señaladas en el Derecho de Familia, se afirma que se puede solicitar la indemnización de los daños morales y patrimoniales originados por la separación o el divorcio, no cubiertos por estos preceptos, en particular el incumplimiento de los deberes matrimoniales.

\section{LA JURISPRUDENCIA}

La doctrina favorable a admitir la indemnización por el daño provocado por el incumplimiento de los deberes matrimoniales ha tenido un reflejo más bien escaso en la jurisprudencia del Tribunal Supremo español. Dejando aparte los casos de responsabilidad civil derivada de la comisión de delitos o faltas y de los supuestos vinculados a la infracción de los derechos de la personalidad, con respecto a los deberes conyugales se ha limitado a reclamaciones de exmaridos por incumplimientos del deber de fidelidad conyugal por sus cónyuges, que habían dado lugar a la concepción de hijos que durante un tiempo ellos habían creído suyos y que posteriormente resultaron no serlo.

En tales decisiones, el máximo tribunal ha señalado que la infidelidad conyugal, si bien constituye una infracción merecedora de innegable reproche, no es susceptible de generar derecho a reparación económica alguna, en concepto de daños morales. Sin embargo, en la primera sentencia dictada por aquel, y al menos de forma indirecta, ha logrado sentar las bases para establecer un principio de indemnización del daño provocado por el incumplimiento de los deberes matrimoniales si el cónyuge infractor que ha provocado el daño ha actuado con dolo.

Dichas sentencias corresponden a las dictadas el 22 y 30 de julio de 1999. Cierto es que la fundamentación jurídica de una y otra no son enteramente coincidentes. En la primera, el Tribunal Supremo rehúsa condenar a la mujer sobre la base del artículo 1902 del Código Civil porque no aprecia una conducta dolosa de su parte. ${ }^{4}$ Así, la sentencia del máximo Tribunal rechaza la pretensión indemnizatoria del padre engañado por haberle ocultado la paternidad, ya que señala que no puede imputarse dolo a la mujer. Esto dio lugar a un recurso ante el Tribunal Constitucional, que no se pronunció sobre el fondo del asunto. Mientras que la segunda sentencia estableció la doctrina de que el incumplimiento de los artículos 66, 67 y 68 del Código Civil, que se refieren a los derechos y deberes de los cónyuges, solo determina la ruptura de la unión, no una reparación indemnizatoria y mucho menos basada en el artículo 1101 del mismo texto, que concierne a la responsabilidad contractual. ${ }^{5}$

Así, aunque en ambas resoluciones se determina el incumplimiento de los deberes número 35 al articulado del Proyecto de Ley 121-00016 por la que se modifica el Código Civil en materia de separación y divorcio, presentada en el Congreso de los Diputados por el grupo parlamentario mixto, en la que se propone añadir en la redacción dada al artículo 97 del Código Civil, a la hora de fijar la pensión compensatoria, el incumplimiento de las obligaciones y deberes conyugales. VIII legislatura, BOCG, Congreso de Diputados, serie A: Proyectos de Ley, n. 16-18, 15 mar. 2005, p. 30-31.

4 El artículo 1902 del Código Civil español señala que "el que por acción u omisión causa daño a otro, interviniendo culpa o negligencia, está obligado a indemnizar el daño causado" (ESPANHA, 1889).

5 SSTS, 1a, 22 de julio 1999, FD $3^{\circ}$ (RJ 5721) y 30 de julio de 1999, FD $4^{\circ}$ (RJ 5726). 
matrimoniales, no se da lugar a la indemnización. El mérito, en consecuencia, es que desde que se dictaron estas dos sentencias - hace ya más de diez años- se han pronunciado numerosas decisiones en apelación en casos de este mismo tipo. En general, se aprecia que las Audiencias Provinciales han acatado la doctrina del Tribunal Supremo en lo relativo a que no es indemnizable el daño moral provocado por la infidelidad conyugal; sin embargo, igualmente conceden la indemnización sobre la base de la sentencia de 22 de julio de 1999 respecto a la conducta dolosa de la mujer al ocultar la verdadera paternidad, pues ha sido interpretada por casi todas ellas -salvo la sentencia de la Audiencia Provincial de Segovia de 30 de septiembre de 2003- como una posibilidad de atribuir responsabilidad al cónyuge infiel si se demuestra este factor de imputabilidad.

En efecto, en el primer caso referido, el marido solicita indemnización por el daño moral sufrido por haberle ocultado la verdad sobre su paternidad y por los alimentos otorgados al hijo que creía suyo durante 15 años. Desestimada la demanda, el marido recurrió ante el Tribunal Supremo alegando la infracción, por inaplicación del artículo 1902 del Código Civil, y argumentando en los hechos que se había visto sometido a un procedimiento de impugnación de paternidad en el que su cónyuge reconoció que había mantenido relaciones extramatrimoniales y que de ello había resultado el nacimiento de un hijo que consideraba propio y que no lo era. Dicha situación le ocasionó "unos daños morales innegables al haber sido humillado y lesionado en su honor y dignidad". El Tribunal Supremo estimó que si bien la mujer podía tener sospechas de que el hijo que esperaba no era de su cónyuge, nunca tuvo "un conocimiento pleno y de total certidumbre" y concluyó que, al no haber dolo por parte de esta, no podía accederse a ninguna de las pretensiones del marido. ${ }^{6}$

En la segunda sentencia, que se dicta unos días después, el 30 de julio de 1999, el tribunal se refirió a un supuesto de hecho muy parecido. En la acción impetrada por el marido contra su excónyuge, se solicita indemnización basado en la infracción de los artículos 67 y 68 del Código Civil español, ${ }^{7}$ en particular por la violación del deber de fidelidad, amparado en el artículo 1101 del texto legal citado, y en la ocultación de la paternidad; ${ }^{8}$. Ello se ve impulsado por el hecho de la impugnación de la paternidad de los hijos matrimoniales, solicitada por la excónyuge y madre, después de haberse producido la separación matrimonial y posterior divorcio por cese efectivo de la convivencia; el actor, entre las pretensiones, también reclama una cantidad por los alimentos prestados a quienes resultaron no ser sus hijos. La demanda fue acogida parcialmente por el tribunal de primera instancia, pues consideró que el actor había sufrido un engaño sobre los que creyó que eran sus hijos, por lo que había pasado de tener familia a no tenerla, con el sufrimiento psíquico y espiritual que ello conllevaba. Dicho fallo fue objeto de apelación a petición exclusiva de la mujer, la Audiencia Provincial acogió íntegramente el recurso, rechazando en definitiva la pretensión. El

6 SSTS, $1^{\text {a }}, 22$ de julio 1999, FD $3^{\circ}$ (RJ 5721) y 30 de julio de 1999, FD $4^{\circ}$ (RJ 5726).

7 Los artículos 67 y 68 del Código Civil español establecen, respectivamente, que "el marido y la mujer deben respetarse y ayudarse mutuamente y actuar en interés de la familia" y que "los cónyuges están obligados a vivir juntos, guardarse fidelidad y socorrerse mutuamente". (ESPANHA, 1889)

8 El artículo 1101 del Código Civil español señala que "quedan sujetos a la indemnización de los daños y perjuicios causados los que en el cumplimiento de sus obligaciones incurrieren en dolo, negligencia o morosidad, y los que de cualquier modo contravinieren el tenor de aquélla".(ESPANHA, 1889). 
marido presentó recurso de casación, fundado en la infracción de los artículos 67 y 68 del Código Civil en relación con el artículo 1101. Respecto de los primeros, el exmarido señalaba que el deber de fidelidad "es una obligación contractual, que tiene su origen en el contrato de matrimonio y que la esposa viene obligada a cumplir". En cuanto a los daños morales, indicaba "no solo que ha vivido en engaño permanente, sino que el resultado final del propio engaño ha sido la pérdida de los hijos, así como un sufrimiento psíquico o espiritual de ver venirse abajo todos sus proyectos".

Frente a este planteamiento, el Tribunal Supremo hace suya la argumentación del tribunal de apelación y asevera que "indudablemente, el quebrantamiento de los deberes conyugales especificados en los artículos 67 y 68 del Código Civil, son merecedores de un innegable reproche ético-social", desaprobación que, tal vez, se acentúe más en aquellos supuestos que afecten el deber de mutua fidelidad, en los que, asimismo, es indudable que la única consecuencia jurídica que contempla la legislación española es la de estimar la ruptura como una de las causas de separación matrimonial en su artículo 82, pero sin asignarle, en contra del infractor, efectos económicos, los que de ningún modo es posible abarcar dentro del caso de pensión compensatoria que se regula en el artículo 97, como tampoco su exigibilidad dentro del precepto genérico del artículo 1101, por más que se estimen como contractuales en razón de la propia naturaleza del matrimonio, pues lo contrario llevaría a estimar que cualquier causa de alteración de la convivencia matrimonial obligaría a indemnizar; discurriendo "que el daño moral generado en uno de los cónyuges por la infidelidad del otro, no es susceptible de reparación económica alguna", lo cual origina la imposibilidad de atribuir al tribunal a quo haber infringido los artículos 67 y 68, en relación con el artículo 1101 del Código Civil español. ${ }^{9}$

Ha de resaltarse de los argumentos de la primera sentencia que el tribunal rechaza la pretensión porque la mujer demandada no había ocultado intencionalmente la verdad a su marido, mientras que en la segunda resolución sí lo sabía, pese a lo cual el Tribunal Supremo considera este hecho como irrelevante, pues el daño reclamado está íntimamente vinculado a la infracción del deber de fidelidad y la propia sentencia declara expresamente que no produce la obligación de indemnizar el daño moral provocado al otro cónyuge. Por lo tanto, la posición del Tribunal Supremo en esta segunda sentencia es clara en el sentido de negar la indemnización solicitada, aludiendo a la aplicación exclusiva de las sanciones o efectos expresamente previstos por el legislador para el incumplimiento de los deberes conyugales y a la proliferación de demandas, en circunstancias de que lo que pretendía el demandante era la reparación de los daños a consecuencia de la infracción de tales deberes jurídicos.

A partir de ahí se establece que no ha de indemnizarse el daño moral provocado por el incumplimiento del deber de fidelidad, porque falta la conducta dolosa de la mujer, tendiente a ocultar la identidad del padre del menor nacido fuera del matrimonio y, por ende, el principio de que para reparar los daños entre cónyuges, éstos han de ser cometidos con dolo, de manera que los daños culpables no se indemnizan.

La explicación de ello, según apunta Rodríguez Guitián (2011,p. 738), radica en que si bien

$\overline{9 \text { El artículo } 1101}$ del Código Civil español. (ESPANHA, 1889).

SCIENTIA IURIS, Londrina, v. 22, n. 3, p. 160-180, nov. 2018. DOI: 10.5433/2178-8189.2018v22n3p160 
en el ordenamiento español el artículo 1902 del Código Civil exige culpa o negligencia y no dolo, en las relaciones familiares no se aplica esta disposición, sino que se requiere un agravamiento de la responsabilidad. Roca, en cambio, duda que este sea el motivo para negar la indemnización, pues como se ha visto en la segunda decisión, sí hay dolo de la ex esposa, ella inicia el procedimiento de impugnación de la paternidad y aun así se rechaza, aunque a través de argumentos distintos, consideran que es sólo para evitar demandas triviales y basadas en incumplimientos menores (ROCA TRÍAS, 1999, p. 561).

Sin embargo, si bien en este caso no hay dolo en la ocultación del hecho a su marido en cuanto la mujer no conoce a ciencia cierta la verdadera paternidad del hijo, no es menos cierto -se ha dicho- que, si se tiene una aventura fuera del matrimonio sin poner los oportunos impedimentos para una futura procreación, se entra en el abanico de posibilidades de un embarazo extramatrimonial (RODRÍGUEZ GUITIÁN, 2003, p. 65).

De ambas ha primado la tesis de que en estos supuestos de ocultamiento de la verdadera paternidad del hijo por parte del cónyuge infiel, el dolo se equipara a la culpa grave y no cabría sino aplicar -en ambas hipótesis- los efectos de la responsabilidad civil contemplados en el ordenamiento jurídico español (FARNÓS AMORÓS, 2007; MENDOZA ALONZO, 2011; ROMERO COLOMA, 2012).

\subsection{Los fundamentos de la admisibilidad por las Audiencias Provinciales}

La admisión de la indemnización ha sido adoptada con posterioridad por la jurisprudencia emanada de las Audiencias Provinciales que, con inéditas sentencias, han acogido la indemnización del daño moral en el ámbito de los deberes conyugales.

Dichas sentencias tratan del adulterio de la mujer, de la ocultación de la paternidad de los hijos que el demandante creía suyos y el posterior descubrimiento de la verdadera filiación; además de la devolución de los alimentos que hasta entonces habían sido pagados.

En efecto, mediante estas primeras resoluciones, los tribunales de apelación van a conceder por primera vez la indemnización por daños de orden extrapatrimonial en casos de incumplimiento de los deberes matrimoniales, acudiendo a la responsabilidad extracontractual, según lo dispuesto en el artículo 1902 del Código Civil español. Estas decisiones son, sin duda, destacables, pues admiten la extensión de la responsabilidad civil, sin que exista norma alguna que lo acoja. Además, que constituyen el recipiente sobre el que se vierte - a contrario sensu- el principio establecido por la sentencia del Tribunal Supremo de 22 de julio de 1999, ya citada, de que se requiere la conducta dolosa de los demandados. Sin embargo, se advierte que esta condición de responsabilidad deviene en otorgarle un cierto carácter sancionatorio a la indemnización, pues en general se concede ante el ocultamiento de la paternidad; la procreación de hijos de manera negligente; el no haberse realizado - ante la duda- las pruebas de paternidad en forma inmediata y la concepción de hijos extramatrimoniales.

En la sentencia de la Audiencia Provincial de Valencia de 2 de noviembre de 
$2004,{ }^{10}$ relativa a una demanda impetrada por el marido contra su exesposa y contra el verdadero padre de tres de los cuatro hijos nacidos durante el matrimonio, se distingue, por un lado, la cuestión de la infidelidad conyugal, respecto a la cual se rechaza la indemnización y se dice compartir plenamente la doctrina del Tribunal Supremo de 1999. En cambio, respecto a la ocultación de la verdadera paternidad de los hijos presuntamente matrimoniales, concluye que los demandados incurrieron en "negligencias en sus relaciones íntimas, ya que conocían que los métodos anticonceptivos que utilizaban no eran seguros". Además, les imputa una conducta dolosa consistente en ocultar la verdad sobre la paternidad de los hijos nacidos durante el matrimonio, permitiendo que se inscribiesen en el Registro Civil como hijos del demandante y que pasaran a formar parte de su familia, situación que mantuvieron durante más de seis años. La sentencia concluye condenando al pago de una cantidad de dinero en concepto de daños morales al considerar que, en este tipo de casos, el "sufrimiento puede ser superior al de la muerte de los menores, al no poder elaborar el duelo como respuesta a la pérdida sufrida". ${ }^{11}$

Las sentencias posteriores siguen la misma línea argumentativa; estiman que hay dolo por parte de la mujer, ya que oculta al marido la verdad sobre la paternidad de los hijos, condenando en ocasiones, junto a la exesposa, al verdadero padre de los hijos atribuidos al demandante. Todas parecen mantener, sin duda, que la mera infidelidad no es un daño indemnizable y que únicamente lo son los derivados de la ocultación de la paternidad del hijo. ${ }^{12}$

En ese sentido, la sentencia de la Audiencia Provincial de Valencia de 5 de septiembre de 2007 se pronuncia sobre la acción de indemnización solicitada por el marido por los daños morales padecidos al conocer que el último de sus hijos no era suyo, alegando una sensación de pérdida asimilable a la muerte de este. ${ }^{13}$

Con posterioridad, se dictan las sentencias de la Audiencia Provincial de Cádiz de 3 de abril de 2008 y de Murcia de 18 de noviembre de 2009. ${ }^{14}$ La primera concede indemnización

10 En la sentencia, el marido de la cónyuge formuló demanda de juicio declaratorio ordinario contra quien fuera su esposa, reclamando una indemnización por los daños y perjuicios ocasionados como consecuencia de que tres de los cuatro hijos que creía suyos y concebidos durante el matrimonio eran, en realidad, hijos biológicos de otro hombre. La Audiencia Provincial estableció, respecto al hecho de la infidelidad, que esta no es indemnizable. Sin embargo, admitió el resarcimiento del daño moral causado por la actuación negligente de los demandados en la concepción de los hijos y por la ocultación dolosa de la paternidad y su falsa atribución al marido, condenándoles solidariamente al pago de 100.000 euros al demandante. Indemnización a un hombre por el daño moral sufrido tras descubrir que no era el padre de 3 de los 4 hijos nacidos durante el matrimonio. Audiencia Provincial de Valencia, secc. $7^{\mathrm{a}}, 2$ nov 2004. La Ley. Sentencia del día $n^{\circ} 59$ de 13 de enero 2005, pp. 7-13. Sentencia de la Audiencia Provincial de Valencia, secc. $7^{\mathrm{a}}, 02.11 .2004, \mathrm{n}^{\circ} 597 / 2004$.

11 Sentencia de la Audiencia Provincial de Valencia, secc. 7 ${ }^{\mathrm{a}}, 02.11 .2004, n^{\circ} 597 / 2004$.

12 Sentencia de la Audiencia Provincial de Santa Cruz de Tenerife, secc. 3a n $^{\circ}$ 389-2009. JUR/2010-79320. Sentencia de la Audiencia Provincial de León, secc. $2^{\mathrm{a}}, \mathrm{n}^{\circ}$ 1-2007. JUR/2007-59972 y de la Audiencia Provincial de Barcelona, secc. $18^{\mathrm{a}}, \mathrm{n}^{\circ}$ 27-2007. JUR/2007-323682. Más recientemente, Sentencia de la Audiencia Provincial de Murcia, secc. $5^{\mathrm{a}}, \mathrm{n}^{\circ}$ 262-2009. AC/2010/60. Otras sentencias acaban absolviendo a la esposa, pero por falta de pruebas de su conducta dolosa. Sentencia de la Audiencia Provincial de Barcelona, secc. 18 ${ }^{\mathrm{a}}, \mathrm{n}^{\circ}$ 510-2005. JUR/2006-163268. Sentencia de la Audiencia Provincial de Barcelona, secc. 14 ${ }^{\mathrm{a}}, \mathrm{n}^{\circ} 597 / 2008$. AC/2009/93, y de la secc. $18^{\mathrm{a}}, \mathrm{n}^{\circ} 472-$ 2009. JUR/2009/464365.

13 Se indemnizó a un padre que descubre no serlo en realidad. La Audiencia Provincial de Valencia también indemnizó a un padre que descubre no serlo, al respecto declara que si bien la infidelidad conyugal no es indemnizable, sí lo es la procreación de un hijo extramatrimonial con ocultación al cónyuge, sancionando de esta manera la "negligencia en la procreación del hijo". No obstante, se tuvo en cuenta el escaso tiempo de convivencia del actor con el menor -no más de un año- para reducir la indemnización fijada en primera instancia (100.000 euros) a la cuantía de 12.000 euros. Sentencia de la Audiencia Provincial de Valencia, secc. 7ª $n^{\circ}$ 466-2007. JUR/2007/340366.

14 Audiencia Provincial de Cádiz, secc. 2a ${ }^{\mathrm{a}} \mathrm{n}^{\circ} 125-2008$. JUR/2008/234675 y Audiencia Provincial de Murcia, secc. $5^{\mathrm{a}}, \mathrm{n}^{\circ} 262-2009$. AC/2010/60.

SCIENTIA IURIS, Londrina, v. 22, n. 3, p. 160-180, nov. 2018. DOI: 10.5433/2178-8189.2018v22n3p160 
por el daño moral provocado por el incumplimiento negligente del deber de fidelidad, con la diferencia de que estima que tal violación es un ilícito susceptible de ser indemnizado vía artículo 1902 del Código Civil español. Para llegar a esta conclusión, la sentencia destaca que los deberes conyugales no son meros imperativos éticos, sino que la protección constitucional del matrimonio como institución obliga al legislador a mantener una sanción jurídica ante la infracción. ${ }^{15}$ Así, afirma que:

[...] en este sentido quien contrae matrimonio adquiere la legítima expectativa de que su cónyuge lleve a efecto los compromisos que adquirió al prestar su consentimiento y debe tener derecho a obtener una indemnización si el incumplimiento cualificado de aquellos le ha causado un daño [...]. Y ello aunque tal posición pudiera generar una inflación de pleitos en tal sentido, considera que no es argumento de peso mientras esté vigente el artículo 1902 del Código Civil [...]. El incumplimiento del deber de fidelidad cualificado por la ocultación a su esposo del mantenimiento de relaciones sexuales simultáneas con otro hombre sin procurar la averiguación de quién podía resultar ser el padre tras su embarazo, justifica la presencia de un ilícito civil susceptible de generar la responsabilidad de la demandada.

Agrega que luego de la reforma 15/2005 existe el deber de "dar contenido jurídico al matrimonio y sancionar las conductas antijurídicas que se den en su seno". ${ }^{16}$ Concluye que deben admitirse "las acciones indemnizatorias que entable cualquiera de los cónyuges por la infidelidad del otro si acredita que con ello se le ha causado un daño moral o económico apreciable, fuera del padecimiento psicológico ordinario que sigue a cualquiera ruptura de la pareja”.

La segunda sentencia, por su parte, junto con condenar a indemnizar los daños morales y patrimoniales causados al exmarido tanto por la mujer como por el padre biológico del hijo extramarital, resalta el tema de la prescripción de la acción, en el sentido de que el término del plazo para el ejercicio de la acción se inicia no desde la ocultación de la verdadera paternidad, sino desde que adquiere firmeza la sentencia que estima la demanda sobre impugnación y reclamación de filiación. ${ }^{17}$

15 En el caso, el marido, tras la separación legal de su mujer, se sometió a unas pruebas de paternidad de las que resultó no ser el padre de los que creía sus hijos. Demandó a su mujer solicitando una indemnización por el daño moral provocado por la infidelidad y por el ocultamiento de la información acerca de sus hijos. En primera instancia se rechazó sancionar la conducta infiel de la esposa y se consideró, asimismo, que no había quedado acreditado el conocimiento pleno de aquella de que su hijo no lo fuese también de su marido. Posteriormente, la Audiencia Provincial declaró "que no resulta precisa la concurrencia de un dolo explícito en la conducta de la demandada para imputarle responsabilidad y que el mero incumplimiento del deber de fidelidad cualificado por el embarazo de un tercero atribuido falsamente por vía de presunción al marido es hecho que por sí mismo genera su responsabilidad civil". Acto seguido, condenó a la demandada a indemnizar al ex marido la cantidad de 31.706 euros por los daños causados por la ocultación de la verdadera paternidad respecto del hijo habido durante el matrimonio; a devolver los alimentos percibidos, aplicando la doctrina del cobro de lo indebido; el pago de los gastos de viaje para ejercitar el derecho de visitas; el 50\% de los gastos sufragados para hacerse la correspondiente prueba de paternidad y una indemnización por los daños psicológicos y morales resultantes, a pesar de que la relación con la que suponía su hija no duró más de un año. Audiencia Provincial de Cádiz, secc. 2a ${ }^{\mathrm{a}} \mathrm{n}^{\circ}$ 125-2008. JUR/2008/234675.

16 Considerando segundo ${ }^{\circ} 2, n^{\circ} 125-2008$. JUR/2008/234675.

17 Frente a la sentencia de instancia que condena a los demandados (mujer y padre biológico) a pagar una indemnización por los daños morales y patrimoniales causados como consecuencia de la ocultación por "aquéllos de la verdadera paternidad al demandante; los primeros interponen recurso de apelación argumentando que en contra de lo que considera la resolución apelada la acción está prescrita, aduciendo que el conocimiento de la paternidad es anterior al 5 de diciembre de 2006 y, cuando menos, desde el año 2001, mientras que la demanda fue presentada el 5 de diciembre de 2007; que se ha valorado erróneamente la prueba del dolo y que no existe daño moral". Audiencia Provincial de Murcia, (fundamento $1^{\circ}$ ), secc. 5a 18.11 .2009 , n 262-2009. AC/2010/60. 
Con un criterio distinto, la Audiencia Provincial de Barcelona, el 16 de enero de 2007, otorga una indemnización al marido por el daño moral derivado de descubrir que no era el padre de la menor que durante cuatro años había creído hija suya. El tribunal estima que la mujer ha incurrido en culpa grave, atendido a que omite adoptar las medidas oportunas dirigidas a determinar la paternidad biológica, ya que pudo y debió sospechar que el padre de la menor podría ser otro distinto a su marido. Primero, porque la madre había mantenido relaciones sexuales simultáneamente con su marido y con su amante y, segundo, porque en los primeros años de matrimonio se había sometido a un tratamiento de fertilidad sin lograr quedar embarazada. Respecto de la procreación de la hija fuera del matrimonio, basa la existencia del daño moral en la pérdida de afectos y en el vacío emocional equivalente o muy próximo a la pérdida definitiva de un ser querido, al descubrir la verdad biológica de la hija, causado - a diferencia de los casos anteriores- por el incumplimiento culpable de la demandada. ${ }^{18}$

En este derrotero, al contrario de las otras decisiones, la Audiencia Provincial de Segovia el 30 de septiembre de 2003 niega la indemnización, basada en el argumento tradicionalmente esgrimido de que los deberes conyugales tienen un carácter puramente ético o moral, es decir, no son una obligación jurídica en sentido estricto, por lo que su falta de cumplimiento no da lugar a un daño resarcible. Así queda de manifiesto cuando subraya que no entran dentro de la indemnización por daño moral:

[...] los daños causados por infidelidades, abandonos o ausencia de lealtad en las relaciones personales, amistosas o amorosas, pues tales supuestos entran en el terreno de lo extrajurídico, no debiendo proliferar categorías de daños morales indemnizables que encarnen intereses que no sean jurídicamente protegibles, y en los que el derecho no debe jugar papel alguno ni debe entrar a tomar partido. ${ }^{19}$

Finalmente, aunque negativa, la sentencia de la Audiencia Provincial de Barcelona, el 31 de octubre de 2008, rechaza la indemnización no sobre la base de que el daño provocado por

18 La sentencia vuelve a tratar la misma cuestión, si bien recalcando, como en los casos anteriores, que el incumplimiento del deber de fidelidad como tal no se indemniza, sino que lo que se concede es el resarcimiento del daño ocasionado como consecuencia de la actuación negligente por parte de la mujer. En esta ocasión, el demandante suscribió un convenio regulador de separación por el que se procedía al reparto de los bienes del matrimonio, en la creencia errónea de que era el padre biológico de su hija menor. Una vez constatado el error, pretendió que se declarase nulo el convenio alegando la equivocación sufrida. Solicitó, además, una indemnización por el daño moral ocasionado. En primera instancia, se rechazaron ambas peticiones. La Audiencia Provincial exigió a la esposa una mayor diligencia a la hora de averiguar la verdadera paternidad de la niña y le recriminó que nada obstaba a que se hubiese hecho las pruebas de paternidad pertinentes para clarificar el hecho con la mayor celeridad posible. La conducta negligente de la madre, que no se hizo las pruebas indicadas, motivó que se le condenase a pagar una indemnización al marido, sustentada en el artículo 1902 del Código Civil, por los daños morales resultantes. También consideró que el marido había sufrido daño moral, el que equipara a la muerte física de un hijo. Considerandos segundo y tercero. Audiencia Provincial de Barcelona, sección 18a, 16.01.2007, n 7-2007. JUR/2007/323682.

19 En esta línea se pronuncia la SAP de Segovia aunque referida a otro deber conyugal. En el caso, la mujer solicitó una indemnización por el sufrimiento que le había causado su marido al abandonar el domicilio conyugal, dada la situación de grave enfermedad que aquella padecía, y a pesar de que el marido había estado satisfaciendo la mitad de la pensión desde que cesó la convivencia entre ambos. La Audiencia denegó el derecho a pedir tal indemnización alegando que si bien es cierto que los deberes de ayuda y socorro mutuos entre ambos cónyuges están proclamados en los artículos 67 y 68 y son comprensivos no solo de lo que materialmente pueda entenderse como alimentación, sino de otros cuidados de orden ético y afectivo, se trata de deberes incoercibles que no llevan aparejada sanción económica alguna -con excepción del deber de alimentos, que en este caso no fue incumplido-sino, como decimos, son contemplados exclusivamente como causa de separación, divorcio y desheredamiento. Audiencia Provincial de Segovia, secc. única, 30.09.2003, n 186/2003. JUR/2003/244422. 
la ocultación de la verdadera paternidad no sea indemnizable, sino porque no es posible apreciar la concurrencia de los requisitos de la responsabilidad extracontractual, en particular el dolo; por lo que señala que "comprende la desazón del actor y no niega el juicio de reproche que merece el incumplimiento del deber de fidelidad y la negligencia de los demandados en siquiera dudar de la posibilidad de una paternidad alternativa, en los tiempos de la concepción". Pero en pos de resolver, concluye que no está prevista en el ordenamiento español la responsabilidad por pérdida de la relación paternofilial, derivada de una infidelidad, para los casos de culpa o negligencia, y que, en este proceso, no está resolviendo una acción de responsabilidad extracontractual por la falta negligente en la práctica de pruebas de filiación extramatrimonial, ni ante una acción de enriquecimiento injusto, para la devolución de pensiones ya pagadas. ${ }^{20}$

Luego, sobre la base de tales argumentos, se pueden identificar los principios jurisprudenciales en torno a los cuales se decide otorgar la indemnización que provoca el incumplimiento de los deberes matrimoniales, haciendo la aprehensión de que se trata más bien de conductas ligadas a tales transgresiones que violaciones propiamente tales.

Entre los que se encuentran los siguientes:

A) No se indemnizan los daños causados por el incumplimiento del deber de fidelidad, salvo que se hubiese actuado con dolo.

El primer principio, y el más importante en lo que atañe a los deberes matrimoniales, es el que establece que el daño originado por la infidelidad no se indemniza. En efecto, en todas las resoluciones se parte haciendo esta declaración. Sin embargo, ante un incumplimiento cualificado, el cónyuge tiene derecho a obtener una indemnización si se le ha provocado un daño moral o económico apreciable, independiente del padecimiento psicológico ordinario que sigue a cualquier ruptura matrimonial.

Dicha extensión de la reparación ha sido posible, gracias a que los comportamientos por los cuales se ha recurrido ante los tribunales indican que ha habido una intención de provocar daño y también al alcance y sentido que los jueces le han otorgado a la derogación de las causas de separación y a la falta de sanción a la infidelidad, tras la entrada en vigor de la Ley 15/2005, que establece la mera expresión de voluntad para romper con el vínculo conyugal.

Sin embargo, el reconocimiento constitucional de la garantía institucional del matrimonio $\mathrm{y}$, por ende, su consideración como derecho fundamental ha logrado que los tribunales, pese al cambio normativo, perseveren en la idea de que se debe dotar de contenido al matrimonio frente a otras instituciones de convivencia, sin perjuicio de que la infracción de los deberes matrimoniales ya no constituya causal de divorcio o separación.

En definitiva, el principio no pretende sino, por una parte, otorgar contenido al matrimonio y, por otra, sancionar las conductas antijurídicas en las que incurra uno de los cónyuges en el ámbito de los derechos personales del matrimonio. Tal responsabilidad queda sujeta -según la

20 Esta vez se rechazó el recurso de apelación interpuesto contra el tribunal de primera instancia respecto de la acción de daños y perjuicios por la pérdida de la relación paterno-filial, fundado en la falta de ocultación dolosa del hecho de la concepción de la menor, pues una vez que la menor desarrolló caracteres físicos propios de la familia del padre, hechas las pruebas comunicó el resultado al actor. Audiencia Provincial de Barcelona, 30.09.2003, n 597-2008. AC/2009/93. 
jurisprudencia- a lo que establecen las normas sobre esta materia y, en ese sentido, será necesaria la condición de un ilícito civil de cierta trascendencia, del daño y de la culpa o dolo de uno de los cónyuges. Pues a partir de ello, se ha llegado -según hemos visto- a la convicción de que existe el derecho a obtener una indemnización si el incumplimiento agravado de los deberes conyugales ha causado un daño.

B) Se indemnizan los daños provocados por la ocultación de la verdadera paternidad, la pérdida de los hijos se asimila a la muerte de éstos.

Frente al principio de que se indemnizan los daños originados por la ocultación de la verdadera paternidad y de que la consecuente pérdida de los hijos se asimila a la muerte de éstos, se plantean dos cuestiones. Por un lado, que la conducta de procrear un hijo extramatrimonial sin revelar la verdad al cónyuge debe sancionarse a través de la indemnización si se tiene la certeza de que el marido no es el padre, tras comprobarlo por métodos científicos. ${ }^{21}$ Las sentencias subrayan esta circunstancia al señalar que:

[...] no puede simplificarse en la existencia o inexistencia de relación entre el actor y el padre biológico, cuando la conducta de éste fue la de, a sabiendas de su más probable paternidad, mantener una total inactividad al respecto permitiendo que se le atribuya la paternidad al demandante, para cuando lo estimó conveniente, destruir el vínculo creado entre padre e hijo.

En cuanto a la demandada, "el temor o miedo a la reacción de su marido, ciertamente no está acreditado como tan intenso e insuficiente que no le permitiera actuar desde un principio, ejerciendo su derecho a separarse y a que se reconociera la verdadera paternidad del hijo". ${ }^{22}$ $\mathrm{Y}$ al contrario, si solo existen posibilidades y sospechas y no un conocimiento pleno y de total certidumbre, no puede concluirse que haya una ocultación de la paternidad y, por ende, un derecho a la indemnización. ${ }^{23}$

Por otro lado, una vez descubierta la verdad, se da por hecho la pérdida de los hijos y, por lo tanto, el daño moral del demandante. Y sobre esa base se ha encuadrado su existencia, prescindiendo de pruebas directas y objetivas, tan solo porque se entiende consustancial a la generalidad de los casos descritos. En consecuencia, se ha llegado a la convicción de que el cónyuge fue objeto de daño moral sin acreditarlo.

Ahora bien, reconociendo que dicha circunstancia no imposibilita legalmente a los tribunales para poder fijarlo, en los hechos debiera acreditarse la afectación psicológica de la víctima.

En definitiva, según se ha visto, se decide en estos casos que cabe la indemnización por la infidelidad y por la afectación psicológica que se produce por el ocultamiento y la pérdida de los hijos, ya que ambas obedecen a los mismos hechos y se enlazan entre sí de manera inseparable,

21 Audiencia Provincial de Cádiz, secc. 2a (considerando segundo n 1), 03.04.2008, $\mathrm{n}^{\circ}$ 125-2008. JUR/2008/234675. 22 Audiencia Provincial de Santa Cruz de Tenerife (considerando segundo), 16.10.2009, n 389-2009. JUR/2010/79320.

Audiencia Provincial de Murcia, secc. $5^{\text {a }}$ (considerando tercero), 18.11.2009, n 262-2009. AC/2010/60.

23 Audiencia Provincial de Barcelona (considerando tercero), 29.09.2005, n 510-2005. JUR/2006/163268. 
aunque se niegue la primera, las circunstancias demuestran que la indemnización se otorga igualmente- por hechos constitutivos de infidelidad.

C) Se indemniza el daño provocado por la actuación negligente en la concepción de los hijos extramatrimoniales

Desmarcándose del requisito del dolo y sobre la base de argumentos de texto, como es que de acuerdo con la culpa o negligencia a que se refiere el artículo 1902 del Código Civil español deben utilizarse, también, estos conceptos en la calificación de la conducta del cónyuge, por ser más amplios que el dolo o la intención maliciosa y porque cualquier hecho dañoso, antijurídico, imputable a una falta de diligencia de quien los comete genera responsabilidad. Los tribunales han resuelto que la omisión de la adopción de medidas dirigidas a determinar la paternidad constituye una negligencia, pues debe presumirse que "si mantiene simultáneamente relaciones sexuales con un hombre distinto del cónyuge y queda embarazada sabe o puede saber que existe más de una paternidad posible". ${ }^{24}$

De ahí que -gracias a la aplicación del precepto citado-se ha modificado la jurisprudencia que hasta ese momento consideraba que la indemnización requería un dolo explícito en la conducta, manteniendo su valor, puesto que en base a éste último se ha logrado sentar el primer principio de la reparación en el ámbito de los derechos personales entre los cónyuges e incluir posteriormente una fórmula que incorpora la culpa para el caso de los daños provocados por el incumplimiento del deber de fidelidad cualificado por el embarazo de un tercero que no es el marido.

D) Los daños patrimoniales derivados del descubrimiento del carácter extramatrimonial del hijo inscrito como matrimonial: no procede la devolución de los alimentos

Las decisiones de los tribunales en esta materia han establecido el principio de que no procede la devolución por parte del hijo como de la madre de las cantidades pagadas por el supuesto padre en concepto de alimentos, fundado en que respecto del hijo existe la obligación de contribuir, atendido el vínculo jurídico que crea la filiación. En tanto, en relación con la madre, se presume que mientras estuvo vigente el matrimonio contribuyó a las cargas comunes, conforme a los artículos 1362 y 1438 del Código Civil español. ${ }^{25}$

Sin embargo, atempera tal principio, la condena aplicada al padre biológico y que lo obliga a la devolución de las cantidades pagadas por este concepto, a partir de la fecha de la interposición de la demanda de reclamación de paternidad, toda vez que la determinación de la verdadera filiación tiene efectos retroactivos y se entiende desde esa fecha que el hijo ha dejado de tener vínculo con el que creía era su padre. Asimismo, lo obliga a la devolución de aquellos alimentos que se hubiesen establecido en la demanda si se ha actuado con dolo. Lo que demuestra que la referida fórmula ha sido reemplazada por una más amplia, como la de que procede la devolución de los alimentos por parte del padre biológico desde la sentencia que declara la verdadera paternidad.

Así, los tribunales han evitado la injusticia que constituye el enriquecimiento o provecho que ha obtenido el padre biológico producto del pago que ha realizado el supuesto padre por

24 Audiencia Provincial de Barcelona (considerando segundo), 29.09.2005, n 510-2005. JUR/2006/163268.

25 Audiencia Provincial de Cádiz (considerando tercero n ${ }^{\circ}$ ), 03.04.2008, n⿳ 125-2008. JUR/2008/234675. Audiencia Provincial de León (considerando cuarto), 02.01.2007, n 1-2007. JUR/2007/59972. 
concepto de alimentos, no existiendo obligación entre este y el hijo que la recibe por falta de causa y en la creencia de que él debía hacerlo porque el derecho lo obligaba.

Al margen de estas decisiones que acogen la indemnización por hechos indicativos de incumplimiento de las obligaciones matrimoniales, se ha de considerar otras dos que permitirían llegar a la misma conclusión porque se accede a la indemnización del daño provocado por la privación del derecho a tener una relación con el hijo, y la segunda, aunque rechaza la reparación por la pérdida de una hija, por los daños morales producidos por la separación; por el deterioro de la fama, honor derivado del conocimiento de la infidelidad de su mujer y, por último, por el daño patrimonial y enriquecimiento injusto que ha significado haber criado, educado y alimentado a una hija que no es propia; esboza desde el punto de vista de la licitud un cuestionamiento a la conducta de la demandada.

La primera corresponde a la sentencia dictada por el Tribunal Supremo español el 30 de junio de 2009, en la que se condena a la madre a pagar una indemnización por el daño moral provocado al padre por haberlo privado de la relación con su hijo, luego de haberse marchado a vivir a otro país e ngresado a una iglesia. ${ }^{26}$ La particularidad de esta sentencia es que, como destaca Rodríguez Guitián (2011, p. 674), la doctrina "ha creído ver en ella la aceptación de la indemnización por transgresión de los deberes de familia, aunque el padre haya obtenido la guarda y custodia de la hija al poco tiempo de haber emigrado la madre con éste a otro país." Por tanto, no habría realmente una obstaculización al derecho de relacionarse del padre con el hijo, excepto en el momento inicial.

La segunda resolución emana del mismo tribunal y data de fecha 14 de julio de 2010, resalta la ausencia de un pronunciamiento respecto si los daños provocados por la infidelidad pueden indemnizarse y si se requiere dolo o no. Tan solo reconoce la dudosa licitud de la conducta de la demandada que cesa con la separación y que los daños ocasionados por una separación conyugal no son indemnizables, para finalmente rechazar la acción de responsabilidad extracontractual porque la acción ha prescrito. En este caso, el Tribunal Supremo conoce de la infidelidad de la cónyuge y del nacimiento de un hijo que no es de quien se ha señalado ser en la inscripción de paternidad. ${ }^{27}$

En conclusión -como puede constatarse- la proyección de las sentencias del Tribunal Supremo no ha inhibido el abandono de la rígida postura inicial que señalaba que el daño provocado por la transgresión del deber de fidelidad, y con ello también de los otros deberes maritales, no era posible de indemnizar.

$\overline{26}$ Tras la ruptura de la relación sentimental con el demandado, la madre decide marcharse con el menor a USA a raíz de su entrada a la Iglesia de la Cienciología. El padre no vuelve a ver al niño desde el 23 de agosto del año 1991. Sentencia Tribunal Supremo, sala civil, secc. $1^{\mathrm{a}}$. RJ/2009/5490.

27 Con fecha 29 de junio de 1973 el demandante y la demandada contraen matrimonio. El 27 de febrero de 1984 es inscrita en el Registro Civil una niña como hija del matrimonio, nacida el 22 del mismo mes y año. Entre ambas partes se sigue un procedimiento de separación, que concluye por sentencia de 12 de julio de 2001, confirmada por sentencia de la Audiencia Provincial de 26 de noviembre de 2001, declarando la separación de dicho matrimonio. A instancias de la mujer, se sigue procedimiento de impugnación de la paternidad, que termina por sentencia de 27 de mayo de 2003, por la que se declara que la niña es hija biológica de una persona distinta al demandante, ordenando la rectificación de la inscripción de nacimiento. En el mismo año el demandante interpone demanda de divorcio, solicitando la custodia de otro hijo en común del matrimonio y la extinción de la pensión de alimentos respecto de la niña que no es hija suya. En septiembre de 2004 el demandante solicita la extinción de la pensión compensatoria que pagaba a su exmujer, al empezar está a convivir maritalmente con un tercero. Sentencia Tribunal Supremo, sala civil, secc. $1^{\mathrm{a}}$. RJ/2010/5152. 
Las Audiencias Provinciales, mediante la aplicación del artículo 1902 del Código Civil español, que se refiere a la responsabilidad extracontractual, han accedido a ella, aunque bajo la premisa arraigada de que no cualquier incumplimiento genera el deber de indemnizar. En conformidad a ello, únicamente han sido resarcidos aquellos daños cuya producción se ha generado a raíz de una conducta dolosa o negligente por parte del cónyuge incumplidor, pues de otro modo se corre el riesgo de la propagación de demandas, cuyo objeto carece de importancia.

Esta doctrina conducirá a que se separe el daño por el incumplimiento del deber de fidelidad de otros que sí se indemnizan, como la ocultación y posterior descubrimiento de la verdadera paternidad biológica, como si fuesen hechos aparte, aunque éstos realmente constituyan una consecuencia directa de dicha infracción. En efecto, este será el razonamiento que seguirán los tribunales sin reparar-algunas veces-en el punto de inflexión que ha provocado en este desarrollo la reforma de 2005 en materia matrimonial.

\section{LA REPARACIÓN DEL DAÑO DESPUÉS DE LA REFORMA DEL 8 DE JULIO DE} 2005

Luego de la reforma del Derecho de Familia efectuada por la Ley 15/2005, por la que se derogan las causas tradicionales de separación o divorcio, entre las que se encontraba el incumplimiento grave o reiterado de los deberes matrimoniales, ha perdido toda consistencia el argumento de que debe rechazarse la indemnización porque sólo cabe arbitrar estas sanciones en caso de contravención de tales obligaciones (ESPANHA, 2015).

Así, suprimidas estas causas se ha recurrido al artículo 1902 del Código Civil español, que se refiere a las obligaciones que nacen de culpa o negligencia, con el objetivo de conferirles alguna trascendencia jurídica en el caso de una infracción cualificada de estos deberes. ${ }^{28}$

De ahí que, desde la entrada en vigor de la ley, las diferencias se han planteado desde dos perspectivas. La primera, en cuanto que al no tener ya que esgrimirse alguna causa por parte del cónyuge que pretende la separación o divorcio y, con ello, haberse eliminado por el legislador la principal consecuencia jurídica que tenía antes de 2005 al incumplimiento de los deberes conyugales, éstos han quedado reducidos a deberes de carácter ético o moral, sin sanción en el ordenamiento jurídico español. ${ }^{29}$

Por el contrario, la segunda, sobre la eliminación del principal efecto del incumplimiento

$28 \mathrm{La}$ nueva regulación de la separación y el divorcio se fundamenta en su necesaria adecuación a los valores y principios constitucionales. En tal sentido, en la exposición de motivos se indica que "[...] la separación y el divorcio se concibe como dos opciones, a las que las partes pueden acudir para solucionar las vicisitudes de su vida en común. De este modo, se pretende reforzar el principio de libertad de los cónyuges en el matrimonio, pues tanto la continuación de su convivencia como su vigencia depende de la voluntad constante de ambos. Así pues, basta con que uno de los esposos no desee la continuación del matrimonio para que pueda demandar el divorcio, sin que el demandado pueda oponerse a la petición por motivos materiales, y sin que el Juez pueda rechazar la petición, salvo por motivos personales". Ley 15-2005, de 8 de julio, por la que se modifican el Código Civil y la Ley de Enjuiciamiento Civil en materia de separación y divorcio. BOE»n. 163, 9 jul. 2005. (ESPANHA, 2005). Pastor Vita (2005, p. 32) indica que con ello "se logra el necesario ajuste de la regulación del divorcio y el respeto al principio constitucional al libre desarrollo de la personalidad, de tal manera que los cónyuges, ya sea de manera conjunta o unilateralmente, sólo tendrán que manifestar ante la autoridad judicial su voluntad de disolver el vínculo matrimonial."

29 "El incumplimiento flagrante de los deberes conyugales en la esfera personal tiene relevancia jurídica múltiple. [...] dichos malos tratos son constitutivos, en la mayoría de los casos, de un ilícito civil. Cuando el ilícito no existe o no está acreditado o no puede acreditarse, las infracciones de los deberes de los cónyuges en la esfera personal son 
de los deberes conyugales - constituir causa de separación y divorcio-, ha tenido como consecuencia que los tribunales han debido aceptar la idea de conferir la indemnización de daños y perjuicios si ha tenido lugar la transgresión de estos deberes y se acredite la existencia de los requisitos de la responsabilidad civil; con esta medida se otorga coherencia al sistema matrimonial, además de que se reafirma el valor jurídico de los deberes matrimoniales.

En apoyo de la primera tesis, algunos autores como Martín-Casals y Ribot señalan que la exposición de motivos de la Ley 15-2005 justifica esta nueva regulación del divorcio en el principio constitucional del libre desarrollo de la personalidad y en la idea de que cuando una persona ha llegado a la convicción de que su matrimonio ya no es cauce de desarrollo de su personalidad, se le debe permitir acudir al divorcio de manera inmediata, pues "el ejercicio de su derecho a no continuar casado no puede hacerse depender de la demostración de la concurrencia de causa alguna" (MARTÍN-CASALS; RIBOT, 2011, p. 544-545). Estas afirmaciones, tanto respecto al reforzamiento del principio de libertad en el matrimonio, como el reconocimiento de mayor trascendencia a la voluntad de la persona para terminar con el matrimonio, excluyen la posibilidad de "realizar un ajuste de cuentas en el momento de la ruptura", aunque se acredite la infracción de los deberes matrimoniales durante la convivencia, porque hacerlo contradice la intención del legislador al derogar el divorcio-sanción en $1981,{ }^{30}$ y posteriormente en 2005 , en el sentido de que, por una parte, se ha definido que no se tomará en cuenta la imputabilidad de las conductas de los cónyuges para la determinación de las medidas compensatorias o indemnizatorias arbitradas por el Derecho de Familia y, por otra, sin embargo, los tribunales han abierto la puerta a la imputación de daños vinculados a esas conductas a través de una indemnización que termina por sancionar al cónyuge incumplidor del deber conyugal.

En cambio, para otros autores que parecieren corresponder a la opinión mayoritaria, el legislador de 2005 solo se ha limitado a suprimir una de las consecuencias del incumplimiento de los deberes conyugales: la posibilidad de solicitar la separación o el divorcio por culpa. Es decir, en el caso de que un cónyuge transgreda los deberes que le imponen los artículos 67 y 68 del Código Civil, una de las soluciones posibles para solventar la cuestión es acudir a la separación o el divorcio, con la ventaja de que en la actualidad no se requiere un juicio de valor por parte de la autoridad judicial acerca de si procede tal solución jurídica, sino que bastará con la propia voluntad

difícilmente sancionables, independientemente de que, en ocasiones y como ha quedado dicho, sean difícilmente identificables. La fidelidad, en ocasiones, se puede infringir con la mente y tal infracción, aun conllevando reproches morales, no es susceptible de sanción jurídica. La ayuda y el socorro mutuo, sobre todo en la esfera de los sentimientos, son de difícil concreción en su identidad. Siendo ello así, una cosa se desprende como cierta: los deberes..., más que mínimos obligados, son metas a alcanzar en el matrimonio, principios rectores, buenos tratos contrapuestos a los malos, mediando, entre unos y otros, una especie de tierra de nadie en la que los cónyuges se soportan, se ayudan más o menos, se respetan y comparten, [...], sin que de tal...cumplimiento tibio de los deberes respectivos, resulten consecuencias jurídicas de ningún tipo.”(ROGEL VIDE, 2005, p. 562-564).

30 En ese sentido, hay que reseñar que la Reforma del Código Civil operada por las leyes de 13 de mayo y 7 de julio de 1981 "pretendió no ser sancionadora del cónyuge 'culpable'. Se ha afirmado por algún sector doctrinal, incluso, que en el régimen actual se pretendió, pero sin conseguirlo plenamente, la implantación de un sistema objetivo de causas de separación. No obstante, aunque, al parecer, no se trata de indagar acerca de la 'culpabilidad' o 'inocencia' de los cónyuges, el factor decisivo situándose, en cambio, en la cesación de la vida en común, hay supuestos en los que puede invocarse la separación en función de situaciones que, sin duda, pueden calificarse de injustas para el cónyuge que las padece. En todo caso, la Reforma del 81 dejó de exigir, al menos con carácter absoluto, la tajante división entre 'culpables' e 'inocentes', si bien se mantienen aún 'causas culpables' o legitimadoras de separación. Pero el legislador no contempla, en ese marco, los daños morales que pueden haberse causado al cónyuge "inocente"” (ROMERO COLOMA, 2003, p. 352). 
del solicitante. La razón de esta modificación legal no radica en la pérdida del carácter jurídico de los deberes conyugales, sino que el legislador ha decidido otorgar una mayor trascendencia a la voluntad de no seguir vinculado al cónyuge, en virtud del respeto al principio del libre desarrollo de la personalidad contenido en la Constitución española.

Es más, en contra de lo que podría esperarse con posterioridad a la modificación, estos artículos -67 y 68- todavía se encuentran en el Código Civil español, pudiendo el legislador haberlos suprimido, sin embargo no lo ha hecho, sino que incluso ha creado un nuevo deber, el de la corresponsabilidad en las responsabilidades domésticas y en la atención y cuidado de terceros, y si bien hay opiniones de que esta introducción carece de eficacia jurídica, no es menos cierto que al no derogar los deberes matrimoniales, más que convertirlos en meros deberes morales, lo que ha hecho es resaltar su carácter jurídico (RODRÍGUEZ GUITIÁN, 2011, p. 702). En el mismo sentido, López De La Cruz (2007, p. 21), De Verda y Beamonte (2003, p. 171).

En consecuencia, siguiendo a Rodríguez Guitián, una vez establecida la libertad como principio cardinal de los cónyuges en el matrimonio, la transgresión de los deberes matrimoniales pasa a constituirse en el hecho desencadenante para otorgar una indemnización si con ello se ha provocado daño al otro cónyuge, o sea, en un título adecuado y suficiente para reclamar la indemnización de los daños vinculados a tal infracción (ocultamiento de la verdadera paternidad, la pérdida de los hijos), entre otros, y si los tribunales españoles admiten la indemnización como una medida más frente al incumplimiento de deberes conyugales, no es para limitar el ejercicio del derecho del cónyuge a no seguir casado o evaluar la causa concreta por la que adopta o produce esa decisión, más siendo esta irrelevante para el derecho, sino para reparar el daño ocasionado a uno de los cónyuges por el incumplimiento de los deberes matrimoniales (RODRÍGUEZ GUITIÁN, 2011, p. 732).

Por otra parte y al margen de cualquier violación de los deberes conyugales, también se ha afirmado, producto de la modificación legislativa y en apoyo de la indemnización, que el matrimonio es un contrato bilateral cuyo cumplimiento no puede dejarse al arbitrio de uno de los cónyuges "[...], el hacerlo amerita el otorgamiento de una indemnización por daños y perjuicios [...] por la ruptura no consensuada." (ASOCIACIÓN DE MUJERES JURISTAS THEMIS, 2004).

En conclusión, como se ha podido verificar, la proyección de la reforma ha permitido que se descarte el obstáculo de la naturaleza jurídica de los deberes matrimoniales y avanzar en un criterio general de que es posible admitir la indemnización en el caso del incumplimiento de los deberes conyugales para dar contenido al matrimonio y otorgar alguna consecuencia jurídica a tal transgresión, además de brindar reparación a través de la indemnización.

\section{CONCLUSIONES}

$1^{\circ}$ No existe en el sistema español, ni aun después de la reforma de Familia 15-2005, un pleno reconocimiento de la responsabilidad civil por el incumplimiento de los deberes matrimoniales, pues si bien hay un principio de aceptación de la reparación en la jurisprudencia y 
en la doctrina mayoritaria en ciertas situaciones, es evidente que persisten varios problemas que oscurecen la aceptación en toda su extensión. Si bien la jurisprudencia española ha determinado que existe un incumplimiento de los deberes matrimoniales, no da lugar a la indemnización, dado que no es indemnizable el daño moral provocado por la infidelidad conyugal. Sin embargo, posterior a la sentencia de 1999 conceden la indemnización, respecto a la conducta dolosa de la mujer al ocultar la verdadera paternidad, por ejemplo.

$2^{\circ}$ Uno de los problemas consiste en conferir la indemnización de este daño como una pena privada que persigue castigar al culpable de la violación.

$3^{\circ}$ Otra dificultad consiste en apreciar la indemnización como una forma de compensar el dolor sufrido por el cónyuge.

$4^{\circ}$ Sin perjuicio de lo anterior, luego de la reforma de 2005 , pierde toda consistencia el argumento de que debe rechazarse la indemnización porque solo cabe arbitrar estas sanciones en caso de contravención de tales obligaciones. Asimismo, ha permitido descartar el obstáculo de la naturaleza jurídica de los deberes matrimoniales y avanzar en un criterio general, a través del cual es posible admitir la indemnización en caso de incumplimiento de deberes conyugales, dando contenido a la figura del matrimonio, y otorgar e imponer consecuencias jurídicas a su transgresión.

$5^{\circ}$ En el ordenamiento español la idea de la reparación por el incumplimiento de los deberes matrimoniales se basa en la existencia de un derecho que ha sido violentado por la conducta dolosa o culpable de uno de los cónyuges, manifestada en el dolor o sufrimiento que este comportamiento pueda provocar.

\section{REFERÊNCIAS}

ASOCIACIÓN DE MUJERES JURISTAS THEMIS. Conclusiones del taller de trabajo de 17 de noviembre de 2004 sobre el anteproyecto de Ley de Reforma del Código Civil en materia de separación y divorcio. 2004. Disponible en: <http:/www.mujeresjuristasthemis.org/ documentos/familia/index $>$. Acesso en: 5 aug. 2018.

CARRASCO, Edison. Manual de legislación sobre violencia intrafamiliar. Santiago: Librotecnia, 2008.

DE VERDA Y BEAMONTE, José Ramón. Efectos económicos de las uniones de hecho en la jurisprudencia española. Revista Chilena de Derecho Privado, Chile, n. 1, p. 149-180, 2003.

DÍEZ-PICAZO, Luis; GULLÓN, Antonio. Sistema de derecho civil. 8. ed. Madrid: Editorial Tecnos, 2002. t. II e IV.

ESPANHA. Ley 15/2005, de 8 de julio. Por la que se modifican el Código Civil y la Ley de Enjuiciamiento Civil en materia de separación y divorcio. Disponíble en: $<$ https://www.boe.es/ diario_boe/txt.php?id=BOE-A-2005-11864>. Acesso en: 6 aug. 2018.

ESPANHA. Real Decreto de 24 de julio de 1889 por el que se publica el Código Civil. Disponible en: < https://www.boe.es/buscar/pdf/1889/BOE-A-1889-4763-consolidado.pdf>. Acesso em: 5 aug. 2018. 
FARNÓS AMORÓS, Esther. Indemnización del daño moral derivado de ocultar la paternidad. Revista para el Análisis del Derecho, Barcelona, n. 4, p. 1-25, 2007.

FERRER RIBA, Joseph. Relaciones familiares y límites del derecho de daños. En: CABANILLAS, Antonio (Coord.). Estudios jurídicos en homenaje al profesor Luis DíezPicazo. Madrid: Editorial Civitas, 2003. p. 1837-1867.

GARCÍA DE LEONARDO, María Teresa Marín. Separación y divorcio sin causa. Situación de los daños personales. Revista Aranzadi de Derecho Patrimonial, España, n. 16, p. 145-162, 2006.

\section{LLAMAS POMBO, Eugenio. Cumplimiento por equivalente y resarcimiento del daño al} acreedor: entre la "aestimatio rei" y el "id quod interest". Madrid: Editorial Trivium, 1999.

LÓPEZ DE LA CRUZ. La incidencia del principio de igualdad en la distribución de las responsabilidades domésticas y familiares: la nueva redacción del artículo 68 del Código Civil tras la reforma operada por la ley 15-2005, de 8 de junio. Revista de Derecho Privado, Madrid, 2007, p. 3-45.

MARTÍN-CASALS, Miquel; RIBOT, Jordi. Daños en derecho de familia: un paso adelante, dos atrás. Anuario de Derecho Civil, v. 64, p. 503-560, 2011.

MENDOZA ALONZO, Pamela. Daños Morales por infidelidad Matrimonial. Un acercamiento al Derecho español. Revista chilena de Derecho y Ciencia Política, vol. 2, Chile, p. 41-64, 2011.

NIETO ALONSO, Antonia. El principio de prevalencia de la verdad biológica en materia de filiación y su superación en el ámbito de la reproducción humana asistida. En: DÍAZ M., Ana (Coord.). Régimen jurídico-privado de la reproducción asistida en España: el proceso legal de reformas. Madrid: Dykinson, 2006. p. 1-40.

NOVALES ALQUEZAR, María. Hacia una teoría general de la responsabilidad civil en el derecho de familia. el ámbito de las relaciones personales entre los cónyuges. Revista Jurídica del Notariado, España, v. 60, p. 197-218, 2006.

PASTOR VITA, Francisco. Algunas consideraciones sobre la ley de reforma del Código Civil en materia de separación y divorcio. Revista de Derecho de Familia: doctrina, jurisprudencia, legislación, España, n. 28, p. 25-56, 2005.

ROCA TRÍAS, Encarna. Familia y cambio social: de la casa a la persona. Madrid: Aranzadi, 1999.

RODRÍGUEZ GUITIÁN, Alma María. La responsabilidad civil en las relaciones de familia. En: IZQUIERDO TOLSADA, Mariano; CUENA CASAS, Matilde (Dir.). Tratado de derecho de familia. Navarra: Editorial Thomson Reuters, 2011. p. 659-735.

RODRÍGUEZ GUITIÁN, Alma María. Función de la responsabilidad civil en determinadas relaciones de convivencia: daños entre cónyuges y daños entre los miembros de la pareja de hecho. Revista de Derecho Patrimonial, nº 10, España, p. 65-93, 2003.

ROGEL VIDE, Carlos. Buenos y malos tratos. Los deberes de los cónyuges en la esfera personal. Revista General de Legislación y Jurisprudencia, España, v. 4, p. 559-572, 2005. 
ROMERO COLOMA, María Aurelia. ¿Es indemnizable la violación de los artículos 67 y 68 del Código Civil? En: HERNÁNDEZ CATALÁN, Gloria (Coord.). En diez años de abogados de familia. Madrid: La Ley, 2003. p. 349-359.

ROMERO COLOMA, María Aurelia. Incumplimientos de deberes conyugales y derecho a indemnización. Madrid: Editorial Reus, 190 p, 2012.

Como citar: OTAROLA, Yasna Elizabeth. El desarrollo del sistema de reparación de los daños entre cónyuges en el derecho español. Scientia Iuris, Londrina, v. 22, n. 3, p. 160-180, nov. 2018. DOI: $10.5433 / 2178-8189.2018 v 22 n 3 p 160$. ISSN: 2178-8189.

Recebido em: 04/09/2018.

Aprovado em: 16/10/2018. 